\title{
Morphogenesis of the Palate in Normal Human Embryos with Special Emphasis on the Mechanisms Involved '
}

\author{
ALPHONSE R. BURDI AND KATHLEEN FAIST \\ Department of Anatomy, 2500 East Medical Building, \\ The University of Michigan, Ann Arbor, Michigan
}

\begin{abstract}
The aim of this study was to re-evaluate the classical description of fusion as the closure mechanism of both the hard and soft palates in normal human embryos. Does the soft palate develop by a posterior continuation of shelf apposition, epithelial lamination and disintegration, and by mesenchymal cell fusion as described for the hard palate? Or does the soft palate develop by proliferation and migration of subepithelial mesenchymal growth centers at the posterior edge of the fused hard palate so that the early furrow which separates the two primordial processes of the soft palate is progressively obliterated by mesenchymal merging at the furrow base?

Observations of human embryos prior to, during, and after palatal closure (7-12 wks, 18-75 mm C-R length) indicated (1) an anteroposterior gradient of palatal closure beginning at the primary palate and (2) epithelial fusion remnants found only in the hard palate regions. These observations suggest that the soft palate develops by a displacement of epithelium by mesenchymal merging rather than by epithelial fusion of the entire secondary palatine processes.
\end{abstract}

The human palate has been traditionally described as forming during the third month of development from the midline fusion of the palatine shelves with each other, with the free margin of the nasal septum, and with the primary palate (Keith, '33; Patten, 53; Kernahan and Stark, '58; Schour, '60; Hamilton, Boyd, Mossman, '62; Wood and Kraus, '62; Ballard, '64; Arey, '65; Maisels, '66). These descriptions further indicated an anteroposterior gradient of closure and epithelial fusion along the entire length of the shelves forming the secondary palate, which includes the hard and soft palates as contrasted to the premaxilla or primary palate.

The purpose of this study is to re-evaluate the traditional description of normal human palatal formation. What are the possible morphogenic mechanisms involved in the early formation of the secondary palate, and, in specific, the formation of the soft palate and uvula? Does the soft palate region develop as a posterior continuation of the epithelial fusion of the more anterior regions of the palatine shelves? Or does the soft palate develop by growth, migration, and coalescence (merging) of subepithelial mesen- chymal centers along the posterior edge of the fused future hard palate? The latter mechanism, unlike palatal shelf fusion, does not involve the sequence of epithelial abutment, lamination, and subsequent breakdown.

\section{MATERIALS AND METHODS}

Thirty-one human embryos ranging in size from 18 to 75 millimeters crown-rump length and in age from 7 to 12 weeks were studied (table 1). This series represented the secondary palate before, during, and after its closure.

Each embryo was routinely fixed in $10 \%$ neutral buffered formalin, histologically prepared and sectioned frontally at either 10 or $15 \mu$. Sections were serially mounted and alternately stained with a Masson triple stain and with hematoxylin and eosin. Each embryo was then studied by (1) light microscopy to describe any developmental tissue changes and (2) by graphic reconstruction. The latter technique is similar to classic waxplate reconstruction. Each serial section was pro-

1 This investigation was supported by research grant HD 00178 from the National Institute of Child Health and Human Development and a National Science Foundation Summer Undergraduate Research Fellowship (GE-6283) to K. F. 
TABLE 1

Developmental and estimated chronologic ages of embryos

\begin{tabular}{|c|c|c|}
\hline$\underset{\text { embryo no. } 1}{\text { Human }}$ & C-R length & Age 2 \\
\hline & $m m$ & weeks \\
\hline EH 650 & 18 & 7 \\
\hline EH 619 & 18 & 7 \\
\hline EH 358 & 19 & 7 \\
\hline EH 933 & 20 & 7 \\
\hline EH 600 & 20 & 7 \\
\hline EH 592 & 21 & 7 \\
\hline EH 739 & 22 & 7 \\
\hline EH 598 & 22 & 7 \\
\hline EH 419 & 23 & 7 \\
\hline EH 880-A & 24 & 7 \\
\hline EH 591 & 25 & 8 \\
\hline EH 938 & 26 & 8 \\
\hline EH 589 & 26 & 8 \\
\hline EH 892 & 27 & 8 \\
\hline EH 840 & 28 & 8 \\
\hline EH 512 & 29 & 8 \\
\hline EH 882 & 29 & 8 \\
\hline EH 15-A & 30 & 8 \\
\hline EH 377 & 32 & 8 \\
\hline EH 946 & 34 & 9 \\
\hline EH 785 & 35 & 9 \\
\hline EH 523 & 36 & 9 \\
\hline EH 479 & 36 & 9 \\
\hline EH 746 & 37 & 9 \\
\hline $\mathrm{EH} 621$ & 38 & 9 \\
\hline EH 17-E & 39 & 9 \\
\hline EH 909 & 40 & 9 \\
\hline EH 18 & 45 & 9 \\
\hline EH 784 & 55 & 10 \\
\hline EH 198 & 58 & 11 \\
\hline EH 628 & 75 & 12 \\
\hline
\end{tabular}

${ }^{1}$ From The University of Michigan Embryological Research collection.

2 Chronologic ages determined upon basis of crownrump length according to Wood and Kraus ('62).

jected and traced at a predetermined magnification $(\times 50)$. A reference perpendicular line was then drawn on each tracing so that it passed through the middle of the frontally sectioned nasal septum and, if present, through the epithelial remnants of palatal shelf fusion which were evident in the midline.

The actual graphic reconstruction of the palatal region called for millimeter-ruled graph paper upon which was arbitrarily placed a line corresponding to the constructed reference line on each tracing. Space on each graph was allotted to equal the thickness of each projected serial section multiplied by the magnification factor, e.g., $10 \mu$ section thickness $\times 100$ times enlargement $=1000 \mu$ or $1.0 \mathrm{~mm}$ of graph space. Then, distances of the dental lamina and enamel organs were measured from the perpendicular on the tracing and each value plotted on the graph paper. In this manner, the contour of the entire dental arch was reconstructed and taken to represent the margins of the developing palatal region. The locations of the future incisive and greater palatine foramina, the greater palatine nerves, the palatine processes of the maxillary bones, and the loss of connection between the palate and the nasal septum were landmarks also indicated on each graphic reconstruction. The number of epithelial fusion remnants per section evident along the midpalatal line was mapped on the graphic reconstruction by a color key : 0-3 remnants - blue, 4-6 remnants - red, 7-9 remnants - green, and orange for ten or more remnants.

\section{RESULTS}

During the seventh and early eight weeks, 18-25 $\mathrm{mm}$ C-R length embryos had separate palatine shelves. At seven weeks in utero (EH 650 and 619), the palatine shelves appeared as slight projections extending medially from each maxillary process. In the nine older specimens of this group (19-25 mm C-R length), each palatine shelf was greater in volume and was obliquely to vertically oriented. Anteriorly, each shelf was thick and triangular in shape and conformed in shape to the lateral contour of the interposed tongue mass. The posterior shelf regions of these same embryos were long, slender, and vertical in position.

The secondary palate was also open in the 26-29 $\mathrm{mm} \mathrm{C-R} \mathrm{length} \mathrm{group.} \mathrm{Unlike}$ the previous group, these five embryos showed a clear regional difference in the position of the palatine shelves. Anteriorly, each shelf was horizontally oriented and grew toward the midline above the tongue. Posteriorly, the palatine shelves remained as slender, vertically oriented projections extending inferomedially to the base of the tongue. This characteristic transition between the anterior and posterior regions was identified by (1) the presence of the nerves descending to the vomeronasal (Jacobson's) organs, (2) the distal extent of the two paraseptal cartilages underlying the anterior-most portion of the septum, and (3) the first indication of vomerine ossification centers underlying the pos- 
terior area of the cartilaginous septum in the midline.

Closure of the secondary palate was first observed at eight weeks in one transitional embryo at $29 \mathrm{~mm} \mathrm{C}-\mathrm{R}$ length ( $\mathrm{EH} 882$ ) and in seven other embryos ranging in crown-rump length from 30 to $37 \mathrm{~mm}$. Regions of the palatine shelves which were horizontally oriented in the younger group were the first palatal shelf segments to contact (1) each other, (2) the primary palate, and (3) the inferior edge of the nasal septum. Subsequent fusion occurred first in the region of the future incisive canal as evidenced by the oblique course of the descending nasopalatine nerves in the canal. Septopalatine contact followed both anteroposterior and superoinferior gradients (figs. 1-2).

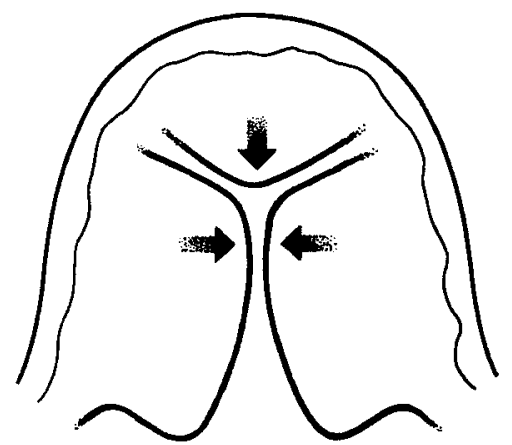

1

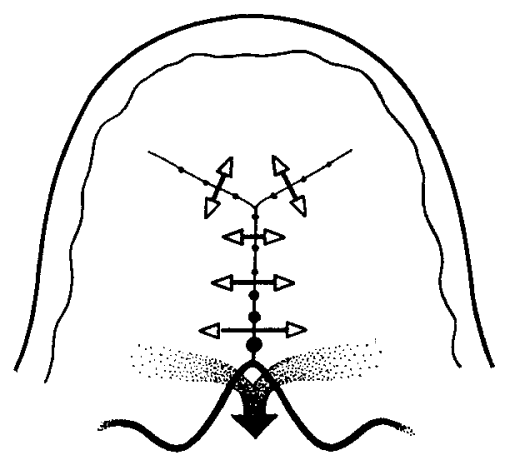

3
The oldest series of embryos (38-75 $\mathrm{mm}$ $\mathrm{C}-\mathrm{R}$ length) verified these gradients of palatine closure observed earlier and also indicated a difference in the developmental fate of the epithelium covering the future hard and soft palate regions of the palatine shelves. The anatomical distinction between these two palatal regions was made by locating (1) the change in direction of the descending palatine nerves from vertical to anteroposterior in the palatal shelf mesenchyme which corresponded in position to the future greater palatine foramen, and (2) the posteriormost connection between the nasal septum and palate immediately anterior to Rathke's pocket which arose as a midline diverticulum from the early oral cavity. The primary differences observed were related

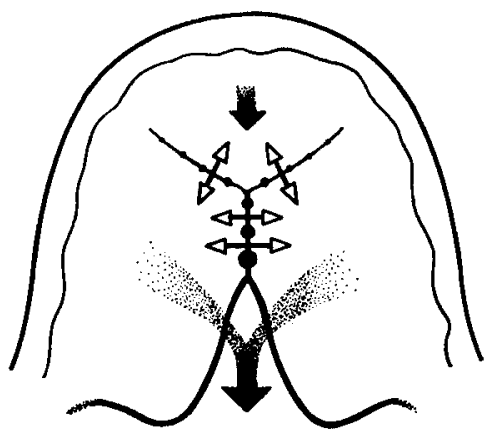

2

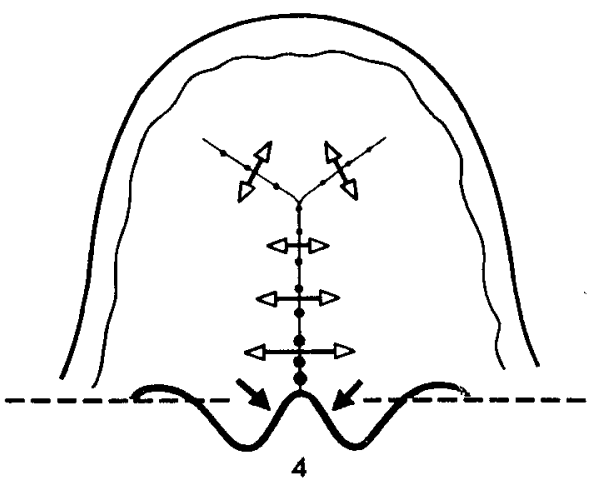

Fig. 1 Fusion mechanism of the hard palate. Inferior view of the palatine shelves showing the gradients of anteroposterior closure (large stippled arrows). Note the sequential changes in size and distribution of epithelial remnants along junction lines and true fusion by intershelf mesenchymal bridges (open arrows) between remnants. Solid arrows in stage 4 represent the merging mechanism of the soft palate. 


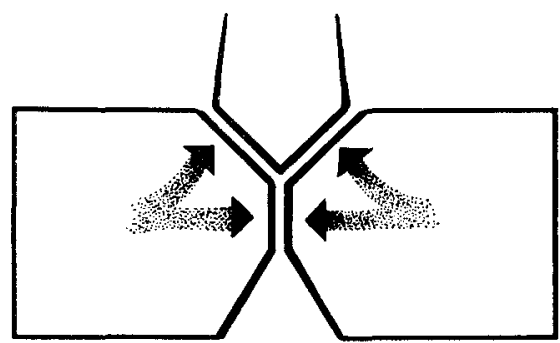

1

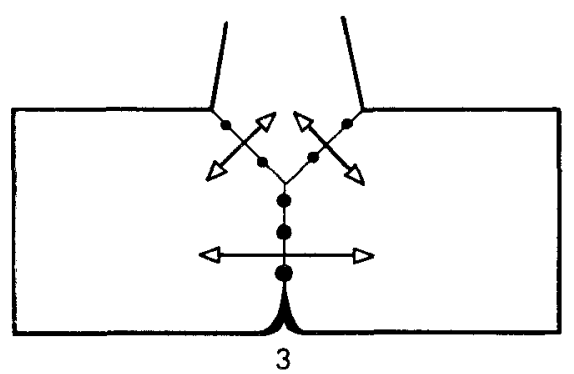

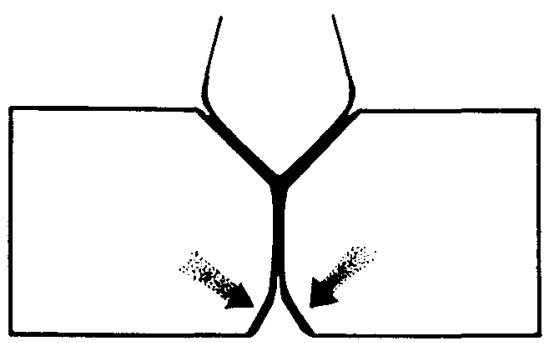

2

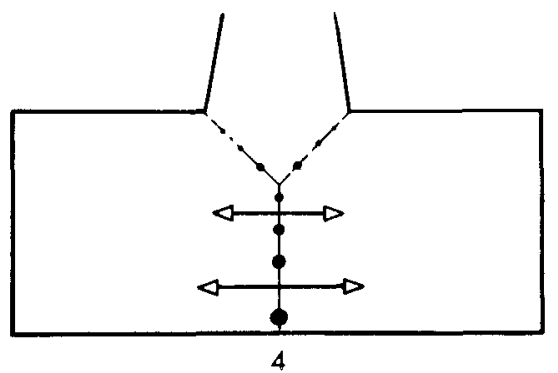

Fig. 2 Fusion mechanism of the hard palate. Stages of septopalatine closure illustrating superoinferior contact fusion gradients as seen in frontal section.

to the sequential development of a laminated fusion epithelium between the shelves, breakdown of the raphe, and, later, the occurrence and distribution of midline epithelial remnants.

Following initial midline contact and the formation of the incisive canal, the abutting layers of cuboidal epithelium covering each palatine shelf fused to form a laminated epithelial raphe. Graphic reconstructions of intermediate and older embryos (30-75 $\mathrm{mm}$ C-R length) demonstrated progressive changes in this early raphe. First, as more posterior regions of the shelves contact each other, the raphe formed earlier in the anterior areas became attenuated and interrupted by mesenchymal cells bridging from one shelf to another, i.e., true fusion. The number of epithelial remnants in the first areas of shelf fusion then decreased from ten or more per serial section to zero to three per section with a concomitant increase in the areas of the intershelf mesenchymal bridges between remaining remnants. According to this developmental gradient, newer areas of shelf fusion had the greatest number of epithelial remnants and the least amount of mesenchymal bridging whereas the older areas of fusion had fewer epithelial remnants and larger areas of mesenchymal cells bridging between shelves. This anteroposterior change in epithelial development was observed for only the developing hard palate.

Neither a midline epithelial raphe nor epithelial remnants were found in the area of newly formed soft palate and uvula. This was clearly demonstrated in the embryos from late nine through twelve weeks, where the soft palate was progressively closing its intershelf furrow without demonstrating a fusion epithelium. The absence of epithelial involvement in the soft palate was compared with the hard palate areas in these same embryos which continued to show a series of epithelial remnants. These remnants were especially pronounced along the junction lines in the posterior half of the hard palate.

The bilateral soft palatine shelves continued to consolidate by a condensation of mesenchyme in the midline. Our graphic reconstructions showed a gradual obliteration of the original intershelf furrow in both the anteroposterior and superoinferior 
directions (fig. 3). Complete closure of the soft palate by mesenchymal bridging was seen at 12 weeks in the $75 \mathrm{~mm} \mathrm{C}-\mathrm{R}$ length embryo.

The abutting surfaces of the palatine shelves and the nasal septum were covered by a single layer of cuboidal cells. This epithelium at eight weeks became progressively stratified and laid on a distinct basement membrane. The outermost layer of cells remained cuboidal. Stratification continued in the oldest embryos studied (55-75 mm C-R length) followed by a clear differentiation of more regional types of epithelium. A non-keratinized stratified squamous epithelium lined the oral surface of the entire palate whereas the septum and the nasal surface of the palate were covered by a pseudostratified columnar epithelium with goblet cells. The stratified epithelium on the oral surface of the palate was thickest in the midline and anterior regions and became thinner and attenuated in the soft palate.

Histological observations of embryos seven through eight weeks (18-32 $\mathrm{mm}$ C-R length) generally showed little cellular differentiation in the bulk of palatal shelf mesenchyme. Older specimens of the series from nine through 12 weeks did show blood vessels close to the oral surface of the shelves. In addition, there were increasing amounts of bone extending toward the midline from premaxillary and maxillary ossification centers as discontinuous spicules.

\section{DISCUSSION}

In the present study, observations of the secondary palate prior to, during, and

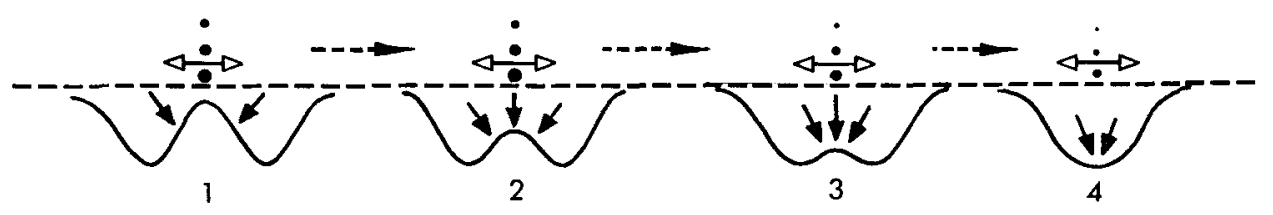

Anteroposterior Merging
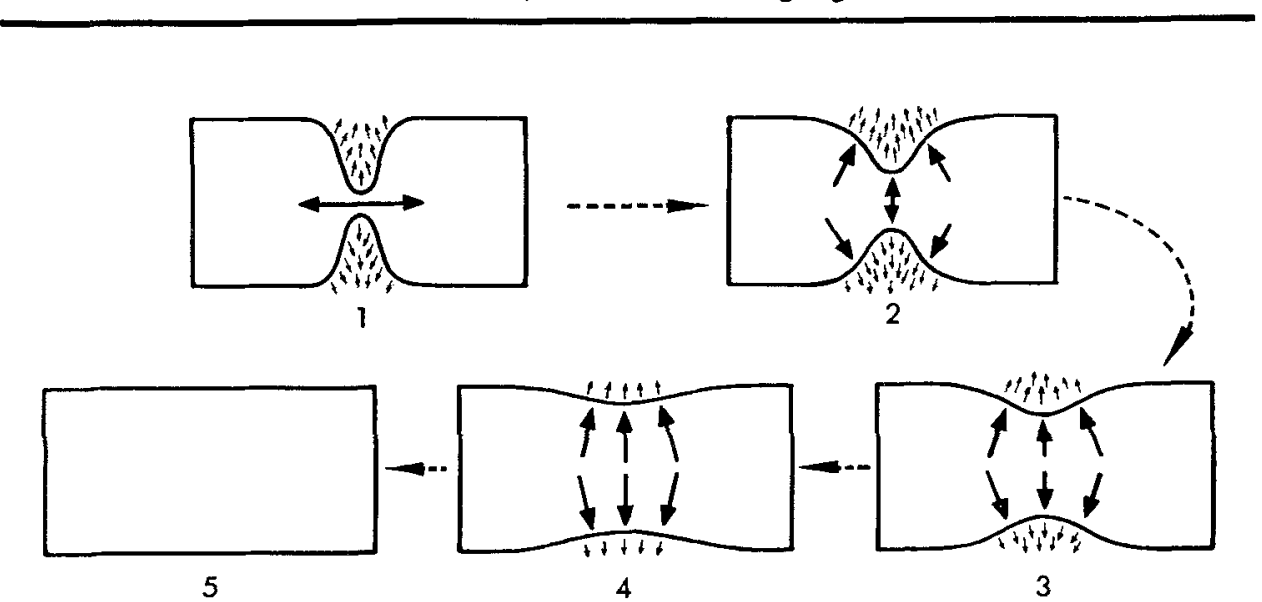

\section{Superoinferior Merging}

Fig. 3 Merging mechanism of the soft palate. In the sequence summarizing anteroposterior merging, stage one is identical to the posterior region of stage four in figure 1 . Directions of subepithelial mesenchymal growth and resultant obliteration of the intershelf furrow are shown by the large-solid merging arrows. Note epithelial remnants remaining anteriorly in the hard palate. The superoinferior merging sequence also illustrates the differential growth of subepithelial mesenchymal centers with the progressive obliteration (small solid arrows) of the furrow which normally indents the superior and inferior surfaces of the developing soft palate. Mesenchymal hypoplasia during any of these stages could lead to submucous clefts. 
immediately following closure suggest that fusion may not be the only mechanism involved as classically described. This classical description of palatal closure involves, in sequence, the midline contact of the palatine shelves with each other and with the nasal septum, the contact, fusion, and lamination of abutting epithelial surfaces, the subsequent breakdown of the laminated midline raphe into epithelial aggregates, and then true fusion of the shelves by mesenchymal cells bridging from one shelf to the other between the epithelial aggregates. These developmental events could only be verified for regions of the secondary palate destined to become hard palate.

The idea that another mechanism is involved in secondary palate closure stems from the developmental occurrence, distribution, and longevity of midline epithelial remnants of the secondary palate. These remnants are characteristically arranged either as an uninterrupted raphe or as isolated epithelial aggregates separated by mesenchymal cells. More importantly, however, they are only found in the hard palate regions of the secondary palate. This observation on the regional distribution of epithelial remnants is supported by Bergengrün ('09) who found that epithelial remnants formed a continuous raphe in the midline of only the hard palate in the embryo. His observations are complemented by other studies. Schumacher ('27) reported that these cornified remnants regress rapidly after birth and usually disappear by the third year; Wood and Kraus ('62) have verified these observations more recently.

In the embryo these residual epithelial cells of the palate can continue to differentiate, proliferate, and gradually acquire the character of enlarged epithelial "pearls" (Barry, '61). Further differentiation of these pearls can result in pathologic median palatine fissural cysts. Interestingly, except for one clinical case that will be cited later, these midpalatine cysts have only been seen, diagnosed, and reported as occurring in the hard palate (Orban, '57; Ash, '61; Thoma, '63; Clark, '65; Kerr and Ash, '65). It seems reasonable to explain this regional limitation of palatal cysts postnatally on the basis that midpalatine epithelial fusion remnants, from which these cysts arise, occur only in the hard palate region of the embryo during palatal closure.

If the entire secondary palate were to close by fusion, and the longevity of resultant epithelial remnants were the same along the entire line of palatal fusion extending from the incisive canal to the uvula, it is both anatomically and clinically significant to ask why midpalatine epithelial remnants are not also found in the soft palate as it closes.

As the secondary palatine shelves unite by fusion in an anteroposterior gradient, the posterior unfused regions of the shelves destined to become soft palate are united by a common base of mesenchyme at the posterior edge of the future hard palate. Thus, after the hard palate fuses two small mesenchymal processes covered by epithelium extend posteriorly toward the oropharynx. Continued development of these mesenchymal processes is dependent on localized rate changes in proliferation, aggregation, and posterior migration of mesenchymal cells in the common base area and in the two soft palate processes springing from it. Obviously, the most critical component in this merging mechanism of the soft palate and uvula is mesenchymal growth and migration.

The essential difference between fusion and merging mechanisms relates to the method by which the palatal shelf epithelium is pushed out or displaced from between the two soft palatal processes by merging of subepithelial growth centers instead of epithelial abutment and disintegration as in fusion. Figure 5 summarizes the two mechanisms of palatal closure suggested by this study. The formation of the soft palate by mesenchymal merging and epithelial displacement provides some explanation as to why epithelial pearls and potential cysts are restricted to the hard palate.

Streeter ('51) recognized the importance of this growth mechanism in smoothing out the various surface swellings and ridges of the human face during the first three months in utero. He considered each swelling as corresponding to growth centers in the underlying common mesen- 
chyme. The furrows that lie between the swellings were progressively obliterated as the proliferation and merging cells filled in at the base of the furrow. This called for a relatively more rapid rate of merging at the furrow base than laterally in the processes surrounding the furrow. Peter ('13) earlier had found that grooves separating the embryonic facial processes do not disappear as a result of epithelial fusion but that they become shallower and eventually obliterated, as the increase in the subepithelial mass produced a new surface level. Stimulated by these early descriptions, Patten ('61) called this a merging mechanism.

That this merging mechanism is not specific to the development of the soft palate is further illustrated by the normal formation of the philtrum of the lip. During the sixth and seventh weeks in utero, two nasomedial processes lie between the nasal pits and are separated from each other along their labial surfaces by a normal midline furrow. This furrow is progressively smoothed out during the eighth week by a merging of its underlying frontal mesenchyme which, if it doesn't occur, can lead to a midline cleft of the philtrum, i.e., a true harelip. The development of the philtrum also indicates how a mesenchymal process and its surface epithelium can be regionally affected by different developmental mechanisms as fusion and merging. Bilateral or unilateral cleft lip stems from a failure in the fusion mechanism between the nasomedial and maxillary processes of the upper jaw during the second month.

Similar to the developing philtrum, the development of the soft palate and uvula involves the obliteration of midline furrows which not only separate the two soft palate processes but also indent the superior and inferior surfaces of the soft palate as it coalesces in an anterior to posterior direction. Defects in the merging mechanism of the soft palate involving mesenchymal hypoplasia, and/or a reversal of localized growth rates, could result in such clinical entities as cleft or bifid uvulae, submucous clefts, and, possibly, uvular cysts.

Patten ('61) explains how a cyst can develop through a defect in the merging mechanism. Unlike the normal obliteration of a furrow by merging, the mesenchymal cells at the base of the furrow are relatively inactive as compared to the cells in the processes themselves. As a result of this abnormal reversal of growth rate, the original furrow is not obliterated but instead deepened by the mesenchymal growth surrounding it laterally. Continued hypoplasia at the base of the furrow and relatively faster growth in the lateral processes would result in a deepened furrow. Varying degrees of cleft soft palates are

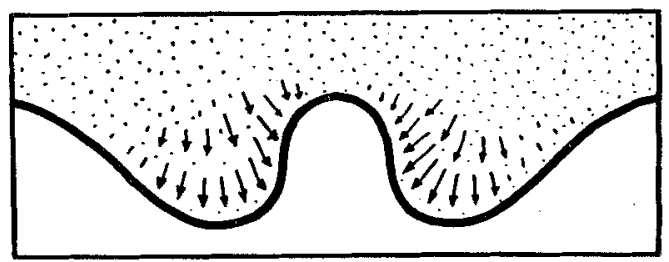

1

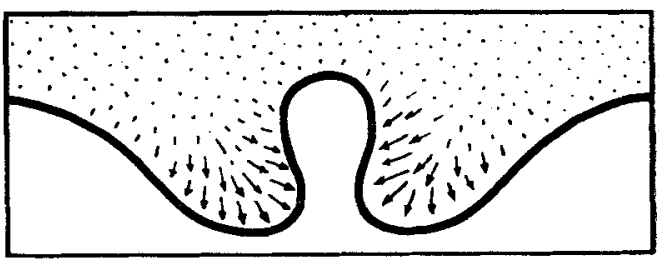

2

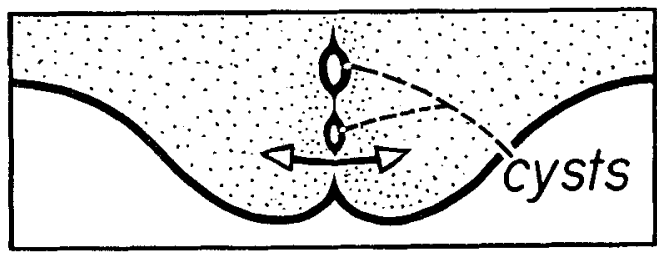

3

Fig. 4 Schematic diagrams suggesting how a reversal of normal gradients of subepithelial mesenchymal merging can result in an epithelial inclusion cyst. Mesenchymal cells at the furrow base are relatively inactive as compared with cells laterally in the two processes of the soft palate (stage 1). As a result of this abnormal rate reversal, the original midline furrow can deepen anteroposteriorly (stage 2). Compare this stage with the normal obliteration of the furrows shown in figure 3. Continued abnormal growth toward the midline could result in a localized fusion epithelium and a potential cyst. Once having formed an isolated cyst, the surrounding mesenchyme can again resume merging and posterior growth of the soft palate (stage 3 ). 
thus explainable (Berans, 1893; Stark, 61; Meskin, Gorlin, Isaacson, '64). The epithelial lining of each side of the furrow could also approximate and contact to form a localized fusion epithelium and possibly a cyst (fig. 4). To our knowledge, there has been only one observation of a single soft palate, i.e., uvular, cyst (Andrews, '62).

\section{LITERATURE CITED}

Andrews, B. F. 1962 Epidermal inclusion cyst of the uvula in infancy. Am. J. Dis. Child., 103: 174-176.

Arey, L. B. 1965 Developmental Anatomy. W. B. Saunders Co., Philadelphia, 7th Ed., Chap. XIII, pp. 213-244.

Ash, M. M., Jr. 1961 A Handbook of Differential Oral Diagnosis. C. V. Mosby Co., St. Louis, Chap. D, pp. 70-71.

Ballard, W. W. 1964 Comparative Anatomy and Embryology. The Ronald Press Co., New York, Chap. 13, pp. 227-240.

Barry, A. 1961 Development of the branchial region of human embryos with special reference to the fate of epithelia. In: Congenital Anomalies of the Face and Associated Structures. Ed. by S. Pruzansky, Charles C Thomas Co., Springfield, pp. 46-62.

Berans, C. 1893 Anomalies of the uvula. Philadelphia Med. Bull., 15: 177-179.

Bergengrün, P. 1909 "Epithelperlen" und Epithelstrange in der Raphe des harten Gaumens. Arch. Entw. Mech. Org., 28: 277-326.

Clark, H. B., Jr. 1965 Practical Oral Surgery. Lea \& Febiger, Philadelphia, 3rd Ed., Chap. 9, pp. 255-297.

Davies, J. 1963 Human Developmental Anatomy. The Ronald Press Co., New York, Chap. 11 , pp. 123-134.

Hamilton, W. J., J. D. Boyd and H. W. Mossman 1962 Human Embryology. Williams and Wilkins Co., Baltimore, 3rd Ed., Chap. X, pp. 203266.

Keith, A. 1933 Human Embryology and Morphology. William Wood \& Co., Baltimore, 5th Ed., Chap. XIII, pp. 182-206.
Kernahan, D. A., and R. B. Stark 1958 A new classification for cleft lip and cleft palate. Plastic and Reconstruct. Surg., 22: 435-441.

Kerr, D. A., and M. M. Ash, Jr. 1965 Oral Pathology. Lea \& Febiger, Philadelphia, 2nd Ed., Chap. 3, pp. 29-57.

Maisels, D. O. 1966 Early orthopaedic treatment of clefts of the primary and secondary palates: A surgeon's view. Cleft Palate J., 3: 76-86.

Meskin, L. H., R. J. Gorlin and R. J. Isaacson 1964 Abnormal morphology of the soft palate: I. The prevalence of the cleft uvula. Cleft Palate J., 1: 342-346.

Orban, B. J. 1957 Oral Histology and Embryology. C. V. Mosby Co., St. Louis, 4th Ed., Chap. 1, pp. 17-33.

Patten, B. M. 1953 Human Embryology. McGraw-Hill Book Co., Inc., New York, 2nd Ed., Chap. 14, pp. 427-459.

1961 The normal development of the facial region. In: Congenital Anomalies of the Face and Associated Structures. Ed. by S. Pruzansky, Charles C Thomas Co., Springfield, pp. 11-45.

Peter, K. 1913 Atlas der Entwicklung der Nase und des Gaumens beim Menschen, mit Einschluss der Entwicklungsstorungen. Jena, Gustav Fischer, vii and 130.

Schour, I. 1960 Noyes' Oral Histology and Embryology. Lea \& Febiger, Philadelphia, 8th Ed., Chap. 2, pp. 29-43.

Schumacher, S. 1927 Die Mundhohle. In: Handbuch der Mikroskopischen Anatomie des Menschen. Ed. by W. VonMollendorff, Springer, Berlin, Vol. 5, pp. 1-32.

Stark, R. B. 1961 Embryology, pathogenesis and classification of cleft lip and cleft palate. In: Congenital Anomalies of the Face and Associated Structures. Ed. by S. Pruzansky, Charles C Thomas Co., Springfield, pp. 66-84.

Streeter, G. L. 1951 Developmental Horizons in Human Embryos. Age Groups XI to XXIII, Carnegie Contrib, to Emb., Reprint Vol. 2.

Thoma, K. H. 1963 Oral Surgery. C. V. Mosby Co., St. Louis, 4th Ed., Chap. 35, pp. 886-895.

Wood, P. J., and B. S. Kraus 1962 Prenatal development of the human palate. Archiv. Oral Biol., 7: 137-150. 
PLATE 
PLATE 1

EXPLANATION OF FIGURE

5 Summary of fusion and merging mechanisms underlying palatal closure. Closure of the future hard palate by fusion is shown by representative frontal sections beginning at the junction of the primary and secondary palates $\left(A-A^{\prime}\right)$ and extending along the entire hard palate (B-B') as indicated by the full length of the nasal septum (heavy-stippled midline area in diagram of inferior view of palate). Serial section $\mathrm{C}-\mathrm{C}^{\prime}$ represents the formation of the soft palate by subepithelial mesenchymal merging in regions posterior to the septum and the greater palatine nerves.

\section{Number key for anatomical landmarks}

(1) nasal cavity
(2) nasal septum
(3) paraseptal cartilages
(4) lateral wing of nasal capsule
(5) dental lamina
(6) eye
(7) epithelial fusion remnants
(8) oral cavity
(9) tongue
(10) Meckel's cartilage
(11) mandible
(12) premaxillary bone
(13) eyelids
(14) forebrain
(15) nerves to vomeronasal organs

(16) greater wing of sphenoid bone

(17) ocular muscles

(18) vomerine bone

(19) maxillary bone

(20) tongue muscle

(21) palatine shelf and blood vessels

(22) body of sphenoid bone

(23) Rathke's pocket

(24) nasopharynx

(25) oropharynx

(26) maxillary blood vessels

(27) soft palate

(28) submandibular gland

(29) hyoid bone 


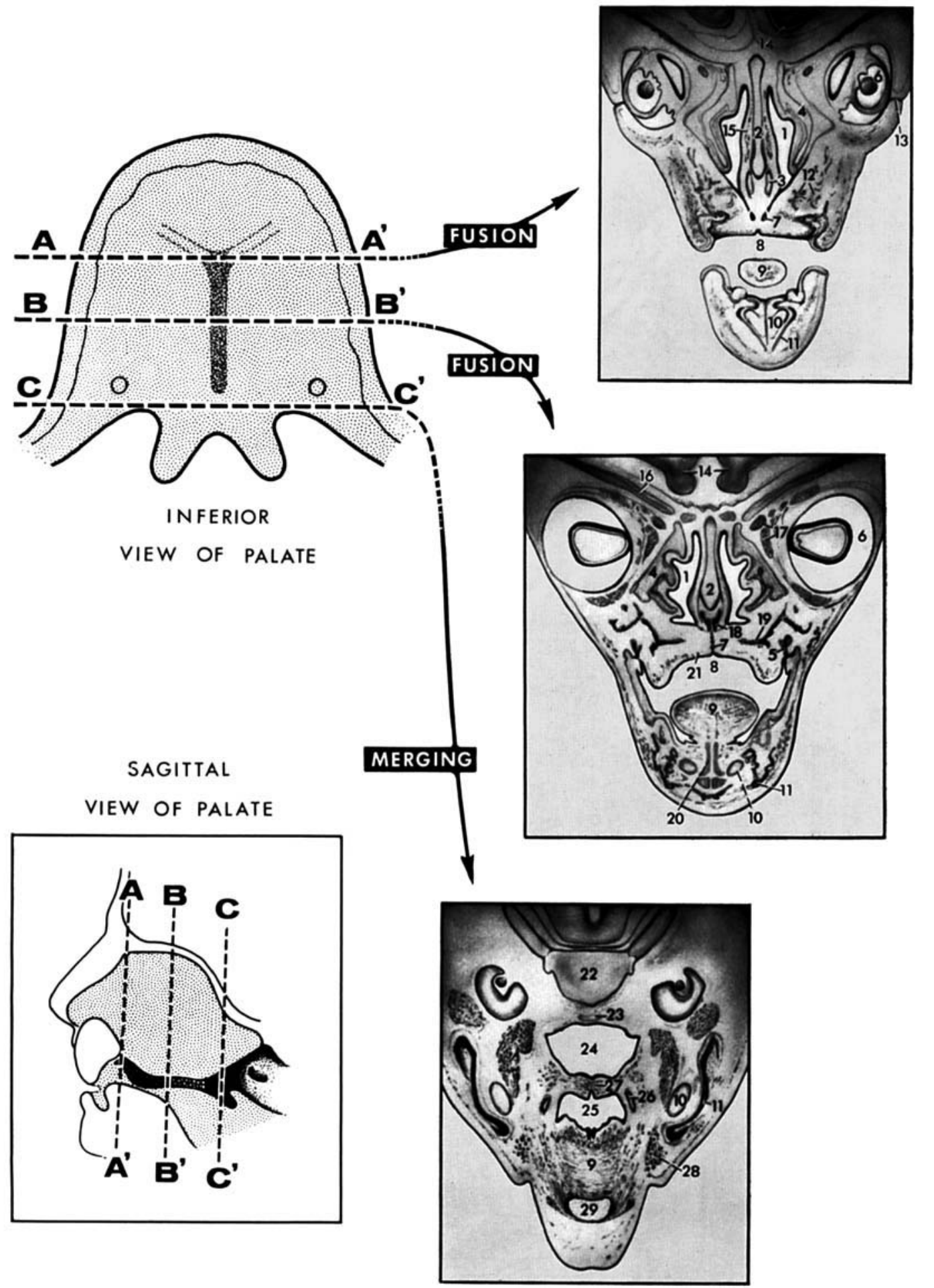

